\title{
Çocukluk Çağı Kanserlerinden Sağ Kalanların İzlemi ve Pediatri Hemşiresinin Rolü
}

\author{
Tuba ARPACI*, Naime ALTAY **
}

$\ddot{O} z$

Çocukluk çağı kanserlerinde 5 yıllık sağkalım oranları önemli ölçüde artmış ve sağ kalanların fiziksel ve psikososyal sağlığının sürdürülmesi ön plana çıkmıştır. Sağ kalan çocuk ve adölesanlar uzun dönemde kanserin kendisi ve tedavi maruziyetine bağlı birçok sorunla karşılaşmaktadır. Tedavinin tamamlanmasından yıllar sonra dahi ortaya çıkabilen kardiyak, endokrin, nörolojik, bilişsel, psikolojik ve sosyal geç etkiler sağ kalanların yaşamında önemli kısıtlılıklara neden olabilmektedir. Uzun süreli izlemler ile geç etkilerin önlenmesi ve erken dönemde saptanması, çocuğun fiziksel ve psikososyal gereksinimlerinin karşılanması, çocuk ve ailenin sosyal yaşama uyumu ve çocuğun ikincil risklerden korunması için sağlıklı yaşam tarzının kazandırılması amaçlanmaktadır. İzlemlerin etkin bir şekilde sürdürülmesi için kanıt temelli yaklaşımlara dayandırılması ve multidisipliner ekip tarafından yürütülmesi gerekmektedir. Sağ kalanlara uzun dönemde bütüncül ve aile merkezli bakımın sunulmasında pediatri hemşiresi önemli role sahiptir. Hemşire standart rehberler 1şı̆̆ında oluşturduğu bireyselleştirilmiş bakım planlarıyla sağ kalanların gereksinimlerinin karşılanmasını sağlamaktadır. Bu makalede çocukluk çağı kanserlerinden sağ kalanlarda izlemin önemi, kapsamı ve izlemlerde hemşirenin rolü ele alınmıştır.

Anahtar kelimeler: Çocukluk Çağı Kanserleri, Sağkalım, Uzun Süreli İzlem, Geç Etkiler, Hemşirelik.

\begin{abstract}
Long-Term Follow-Up of Childhood Cancer Survivors and Nurse's Role

Five year survival rates have greatly increased in childhood cancer and maintaining physical and psychosocial health of survivors has come to the fore in long-term. Survivors face many problems related to cancer itself and treatment exposure. Cardiac, endocrine, neurological, cognitive, psychological and social late effects, which may occur even years after the completion of treatment, may cause significant limitations in their life. With long-term follow-up, it is aimed to prevent and early detect the late effects, to meet the physical and psychosocial needs of the child, to help them for adaptation to social life, and to provide a healthy lifestyle advice to protect the child from secondary cancer risks. In order to following the survivors effectively, it should be based on evidence-based approaches and carried out by a multidisciplinary team. The pediatric nurses play an important role in providing holistic and family-centered care in long-term follow-up of childhood cancer survivors. The nurse ensures survivors' needs with the individualized care plans based on the standard guidelines. In this article, the importance and the scope of the follow-up and the role of the nurse in the follow-up were discussed.
\end{abstract}

Key Words: Chidhood Cancer, Survivorship, Long-term Follow-up, Late Effects, Nursing.

Geliṣ tarihi: 26.11.2019 Kabul tarihi: 27.11.2020

Ç ocukluk çağı kanserlerinde sağkalım oranlarının artmasıyla birlikte çocukların tedavi sonrası iyilik halinin arttırılması öncelikli hale gelmiştir (1). Tedavinin tamamlanmasının ardından sağ kalanların takibi uzun dönemde farklı bir boyut kazanmaktadır. Uzun süreli izlemlerde tedaviye bağlı gelişebilecek fiziksel ve psikososyal geç etkilerin takibi, sosyal yaşama uyumun desteklenmesi ve sağlığın geliştirilmesi uygulamaları izlemlerin odağını oluşturmaktadır $(1,2)$. Bu derleme makalenin amacı, çocukluk çağı kanserlerinden sağ kalanların izleminde pediatri hemşirelerine rehber olacak bir kavramsal çerçeve sunmaktır. Bu doğrultuda makalede uzun süreli izlemin önemi, izlem kapsamında yer alması gereken uygulamalar ve izlemlerde pediatri hemşiresinin rolleri üzerinde durulmuştur.

\section{Uzun Dönem İzlemin Önemi ve Kapsamı}

Gelişmiş tedavi protokolleri ve kanıt temelli bakım uygulamaları sayesinde çocukluk çağı kanserlerinde (ÇÇK) hastalığın türü, tedavi maruziyeti ve hastanın karakteristik özelliklerine göre değişmekle birlikte 5 yıllık genel sağkalım oranları önemli ölçüde artmış ve \%84 düzeylerine ulaşmıştır (3). Ülkemizde sağkalım oranlarını bildiren güncel literatür bulunmamakla birlikte Türk Pediatrik Onkoloji Grubu (TPOG) ve Türk Hematoloji Derneği iş birliği ile yürütülen bir çalışmada tüm ÇÇK'nde 5 yıllık sağkalım oranı \%65 olarak bildirilmiştir (4). Sağkalım oranlarındaki artışla birlikte geç etkilerin önlenmesi ve erken tanılanması, kansere bağlı travma sonrası semptomların değerlendirilmesi ve azaltılması, sağ kalanların kendi sağlığını yönetebilme konusunda teşviki ve bu doğrultuda yaşam kalitelerinin arttırılması önem kazanmıştır. Bu bölümde uzun süreli izlemin kapsamı "Geç etkilerin izlemi", "Sağ kalanların sosyal yaşama uyumlarının desteklenmesi”" ve "Sağlığın geliştirilmesi”" başlıkları altında ele alınmıştır (Şekil 1).

\section{Geç etkilerin izlemi}

Çocukluk çağı kanserlerinde sağkalımı arttırmak ve tedaviye bağlı toksisiteyi en aza indirmek için tedavi protokollerinde sürekli güncellemeler yapılmaktadır (5). Hastalık ve tedavi sürecinin fiziksel, psikolojik, sosyal ve gelişimsel boyutlarda olumsuz etkilerinin olduğu bilinmektedir ve tedavilerin terapötik etkisinin yanında uzun dönemde yol açtığı morbidite yapılan çalışmalarla kanıtlanmıştır (6). Çocukluk çağı kanserlerinden sağ kalanların yaklaşık \%70'inde bir veya daha fazla kronik sağlık sorunu görülmektedir $(7,8)$. Sağ kalanlarda ileri yaşlarda kronik sağlık sorunlarının arttığı ve santral sinir sistemi (SSS) tümörlerinde bu oranın en fazla olduğu bildirilmektedir (9). Çocukluk çağı kanserlerinden sağ kalanlarda yaygın görülen fiziksel geç etkiler arasında kardiyotoksisite, nörotoksisite, kas-iskelet sorunları, endokrin sorunlar, pulmoner sorunlar, gastrointestinal sorunlar, gonadal sorunlar ve ikincil kanserler yer almaktadır $(2,8,10)$. Psikososyal geç etkiler ise depresyon, anksiyete ve Posttravmatik Stres Sendromu (PTSS) ve riskli davranışlar olarak belirtilmektedir (11). Bunlara ek olarak sosyal geri çekilme, kişilerarası ilişkilerde sorunlar, eğitim ya da meslek edinmede güçlük ve ebeveyne bağımlı yaşam gibi psikososyal sorunlar gelişebilmektedir $(1,2)$.

*Dr. Öğr. Üyesi Karamanoğlu Mehmetbey Üniversitesi Sağlık Bilimleri Fakültesi Çocuk Sağlığı ve Hastalıkları Hemşireliği Anabilim Dalı, Karaman. Eposta: tubaarpaci25@gmail.com, ORCID: 0000-0001-8511-8443, ** Prof. Dr. Gazi Üniversitesi Sağlık Bilimleri Fakültesi Çocuk Sağlığı ve Hastalıkları Hemşireliği Anabilim Dalı, Ankara. ORCID: 0000-0003-1524-3390 


\section{Derleme}

Sağ kalanların yaşadıkları bu sorunlar yaşam kalitesini fiziksel fonksiyon, kendilik algısı, beden imgesi, sosyal fonksiyon gibi çeşitli alt boyutlarında olumsuz etkilemektedir $(12,13)$. Sorunların önlenmesi, erken dönemde saptanması, tedavisi ve yaşam kalitesinin yükseltilmesinde sağ kalanların uzun dönem izlemi önemlidir.

Çocukların risk sınıflaması yapılarak izlem sıklığının belirlenmesi, geç etkilerin erken tanılanması bunun için gerekli taramaların, yönlendirme gereken diğer uzmanların/kliniklerin belirlenmesi ve bu doğrultuda çocuk ve aileye bir bakım planı hazırlanması gerekmektedir. Özellikle infertilite gibi geç adölesan ve erişkin dönemde sağ kalanların psikososyal sağlığını etkileyecek sorunlara ilişkin tedavi sürecinden başlayarak önleyici girişimlerin planlanması yararlı olacaktır. Geç etkilerin gelişimi daha önce alınan tedavinin türüne bağlı olduğundan ÇÇK'den sağ kalanların gereksinimleri ve ihtiyaç duyulan uzmanlık türü değişiklik gösterebilir. Sağ kalanların gelişimsel gereksinimleri de düşünüldüğünde izlemlerin nerede sürdürüleceği de önemlidir (pediatrik geç etki kliniği, genç erişkin geç etki kliniği vb.).

\section{Săg kalanların sosyal yaşama uyumlarının desteklenmesi}

Kanser deneyimi ve tedavi süreci çocuk ve adölesanların sosyal gelişimi, duygusal sağlı̆̆ı ve akademik süreçlerini olumsuz etkileyebilmektedir (14). Fiziksel engel, nörobilişsel sorunlar ya da geç etkiler nedeniyle sağ kalanlar sosyal ilişsilerinde güçlük yaşamakta ve sosyal rollerini gerçekleştirmede zorlanmaktadır (15). Hastalık öyküsü, geç etkilerin varlığı veya sağ kalanların bu konudaki kaygıları eğitime devam etme ve meslek edinmelerini olumsuz etkileyebilmektedir. Sağ kalanlar okula geri dönüşte uyum sağlama konusunda kaygılanabilir. Okula dönüş konusunda yaşanan güçlükler arasında "arkadaş ilişkileriarkadaşlardan yabancılaşma duyguları", "akademik performans-ders çalışma konusunda güçlük” (16,17), "akranlarından farklı olmak", "gelecek konusunda belirsizlik duyguları" bildirilmiştir (17).

Sağ kalanlarda kaygı ve sosyal geri çekilme de görülen sorunlar arasındadır. Çocukluk çağı kanserlerinden sağ kalan genç erişkinlerin kaygılarının incelendiği bir çalışmada sağ kalanlar romantik ilişkiler ve evlilik, fertilite, çalışma ve sosyal yaşam, aile ve fiziksel sağlık alanlarında kaygılarını bildirmişlerdir (16). Sosyal yaşantının kesintiye uğraması, sosyal ön yargılar, aileakran ilişkilerinde bozulma gibi nedenlerle sosyal geri çekilme görülebilmektedir $(14,18)$. Bu nedenle çocuk ve adölesanların sosyal yaşama uyumunun desteklenmesi, aile ve akran ilişkileri, ebeveyn tutumları, okul vb. konularda kaygılarını paylaşabileceği bir klinik ortam ve ekip desteği yararlı olacaktır. Öncelikle çocuğun bu konulardaki gereksinimlerinin belirlenmesi bireysel bütüncül bakımın sağlanabilmesi açısından önemlidir. Bu doğrultuda pediatri hemşiresi her izlemde çocuğun yaş dönemine göre gelişimsel özelliklerini de göz önünde bulundurarak genel iyilik hali, psikolojik ve sosyal sağlı̆̆ını psikometrik ölçüm araçlarıyla değerlendirebilir ve gereksinimlerini sorgulayabilir. Sosyal sağlı̆̆ın desteklenmesi açısından tedavinin tamamlanmasının ardından sosyal yaşamda onları nelerin beklediği, hangi konularda soru işaretleri olabileceği, sosyal becerilerini nasıl geliştirebilecekleri bu kapsamda hangi faaliyetlere katılabilecekleri gibi konuları içeren eğitim materyalleri ve destek programları geliştirilebilir. Özel gereksinimi olan çocuk ve ebeveynler için destek grupları ve uzmanlardan yardım alınması sağlanabilir.

\section{Să̆lı̆̆ın geliştirilmesi}

Sağ kalan çocuk ve adölesanlar ileri yaşlarda sağlık sorunları açısından risk altında oldukları için sağlığı geliştirici davranışların kazanılması ve sürdürülmesini teşvik etmek önemlidir. Başlıca sağlık sorunları arasında yer alan obezite, metabolik sendrom, kardiyovasküler sorunlar ve ikincil kanserlerin önlenmesinde sağlıklı beslenme, düzenli fiziksel aktivite ve riskli alışkanlıklardan uzak durmak gibi sağlığı geliştirici yaklaşımlara izlem rehberlerinde ve modellerinde yer verilmelidir (2,19). Sağ kalanların sağlı̆̆ın geliştirilmesinde öncelikli yaklaşımlardan biri düzenli fiziksel aktivite alışkanlığının kazandırılmasıdır. Fiziksel aktivitenin genel yararlarının yanında sağ kalanlarda fiziksel, sosyal ve bilişsel işlev alanlarında iyi yaşam kalitesiyle ilişkili olduğu belirlenmiştir (20). Sağlıklı beslenme tarzının sağ kalanların metabolik parametrelerini olumlu etkilediği bilinmektedir (21). Sağ kalanların sağlıklı besinlerden zengin dengeli bir diyet ile tedavi sonrası doku iyileşmesi hızlanacak, D vitamini, kalsiyum gibi desteklerin yeterli alınması da çeşitli geç etkilerin (büyüme, kemik sağlığı gibi) önlenmesini kolaylaştıracaktır $(2,22)$. Özellikle erken çocuklukta ebeveynlerin yaşam tarzı çocuğun beslenme ve aktivite gibi alışkanlıklarını etkileyecektir. Sağlığın geliştirilmesine yönelik eğitim ve danışmanlık programlarında aile merkezli yaklaşım benimsenerek tüm ailenin sağlıklı yaşam tarzının kazanılması konusunda desteklenmesi gerekmektedir. Sağ kalanlar tamamen iyileştiği düşüncesiyle gelişebilecek risklerin yeterince farkında olmayabilir. Sigara-alkol kullanma, riskli cinsel davranış gibi riskli davranışlara eğilim artabilir (23). Farklı gelişimsel dönemlerde bu eğilim değişiklik göstererek özellikle gelişimsel dönem özellikleri de düşünüldüğünde adölesan ve genç erişkin dönemde artış gösterebilir $(23,24)$. Bu nedenle sürekli eğitim ve danışmanlık önem kazanmaktadır.

İzlemler kapsamında sağ kalan çocuk ve adölesanların sağlığı geliştirici davranışlara ilişkin sürekli olarak bilgilendirilmesi ve desteklenmesi gerekmektedir. Bunun için özellikle yaş grubuna göre davranış geliştirmeyi teşvik edecek yaklaşımların tercih edilmesi önem kazanmaktadır. Çocuk ve adölesanların ilgisini çekecek ve davranışı pekiştirecek girişimlere yer verilmesi davranışın kazanılması için motivasyonu arttıracaktır. Litertürde çeşitli programlar, videoanimasyonlar, web ve sosyal medya destekli girişimlerle sağlı̆̆ı geliştirici davranışlara ilişkin uygulamaların yararı bildirilmiştir (25). Sağ kalanlara yönelik bireysel sağlıklı yaşam hedefleriyle birlikte bu tarz girişimlerin izlemlere entegre edilmesi sağlıklı yaşamı teşvik edecektir. 


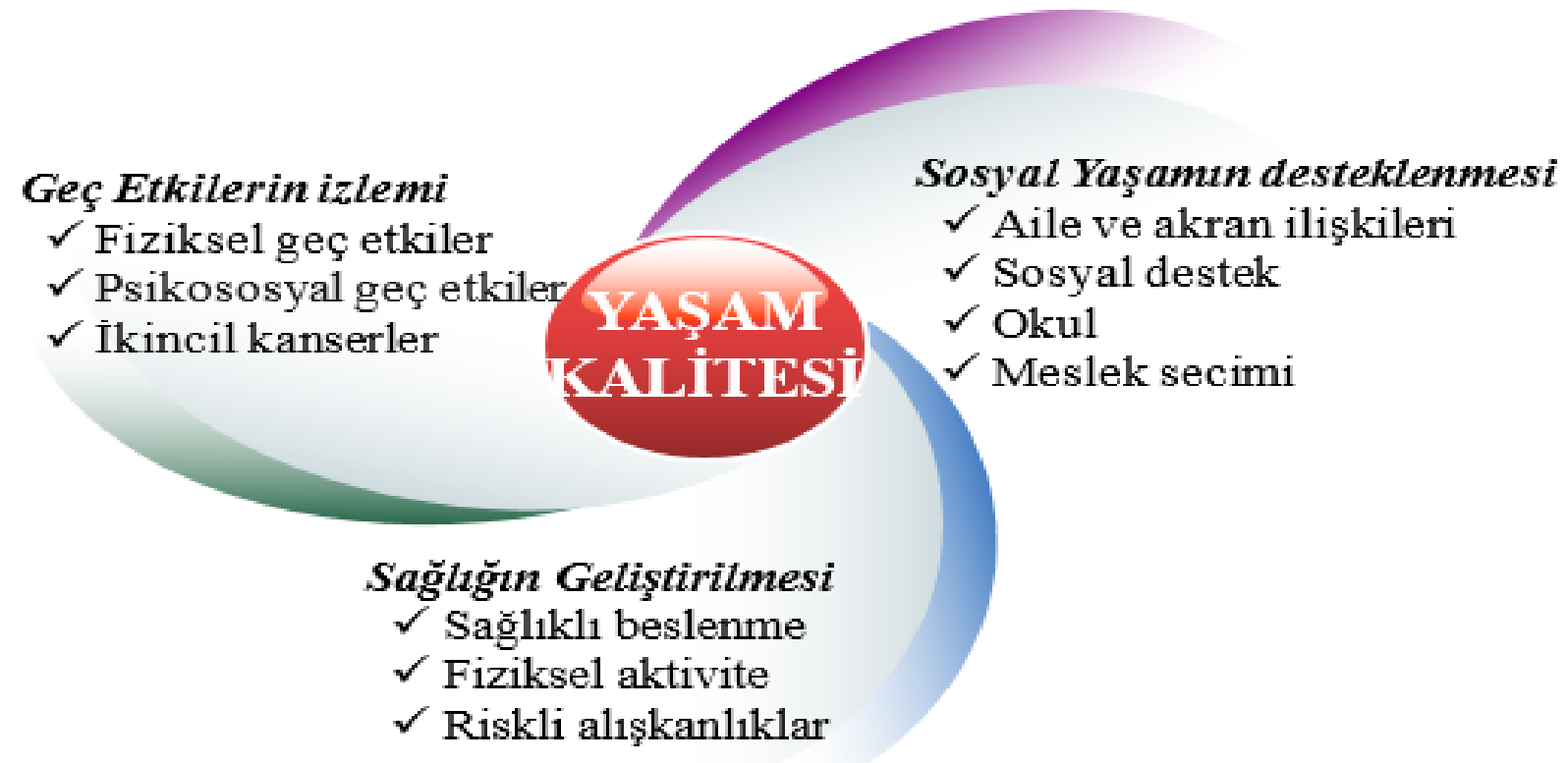

Şekil 1. Çocukluk Çağı̆ Kanserlerinde Uzun Süreli İzlemin Kapsamı $(1,2,11,25)$

\section{Uzun Dönem İzlemde Standartların Geliştirilmesi}

Tedavi sonrası dönemde uzun süreli izlemlerde standart bakımın oluşturulması ve etkili bir şekilde yürütülebilmesi için izlemlerin kanıta dayalı rehberlerle desteklenmesi ve uygun izlem modelinin belirlenmesi önem kazanmıştır. Bu bölümde izlemlerin yürütülmesi için geliştirilmiş rehberler ve izlem modellerine yer verilmiş̧ir.

\section{Uzun dönem izlem rehberleri}

Çocukluk çağı kanserlerinde güncel tedavi yaklaşımlarıyla tedavilere gereksiz maruziyeti önlemek ve bu sayede geç etki riskini azaltmak hedeflenmektedir (2). Kanserin türü ve hastayla ilişkili faktörlere bağlı olarak tedavi maruziyeti değişiklik göstermektedir. Bu nedenle tedavi maruziyetine göre hastaların hangi riskler açısından ne sıklıkla ve ne kadar süreyle takip edilmesi gerektiğine ilişkin standartlara ihtiyaç duyulmuştur. Uzun süreli izlemlerin etkinliğini ve sağ kalanların yaşam kalitesini arttırmak amacıyla standart bakımının sunulması için kanıta dayalı izlem rehberleri geliştirilmiş ve bu rehberlerin uluslararası geçerliğini ve uyumunu sağlamak için çeşitli iş birlikleri yapılmıştır (26).

Çocuk Onkoloji Grubu (Children's Oncology Group) uzun dönem izlem rehberi maruziyete dayalı yaklaşımı esas alarak hangi tedavi ve dozunun ne tür geç etkilere neden olabileceği ve hangi tarama testlerinin yapılması gerektiği konusunda öneriler sunmaktadır (2). Tüm geç etkilerin bütüncül değerlendirildiği ve özellikle tüm tedavi maruziyetlerinde gelişme riski olduğundan psikososyal geç etkilerin ayrıca ele alındığı görülmektedir. Sağlığın geliştirilmesine yönelik girişimlere de yer verilmektedir. Rehberde riske dayalı bireyselleştirilmiş bir izlem ve tarama programının oluşturulması, bunun için sağ kalan çocuğun kapsamlı bir tanı-tedavi kimliğinin hazırlanması önerilmektedir (2). Bunun yanında İskoç Ulusal Rehberi (SIGN, 2013), Hollanda Çocuk Onkoloji Grubu (Dutch Childhood Oncology Group, 2010) ve Birleşik Krallık Çocukluk Kanserleri ve Lösemi Grubu (UKCCLG) uzun dönem izlem rehberleri de bulunmaktadır (26).

İzlemlerin sürdürülmesine ilişkin çeşitli stratejiler bulunmakla birlikte uygulamada standart rehberlerin olmayışı kliniklerde izlemlerin planlanması, organizasyonu (izlemlerin nerede, kim tarafindan, ne sıklıkla sürdürüleceği gibi) ve yürütülmesinde yetersizliklere neden olacaktır. Kanıt temelli yaklaşımlar ve alan uzmanlarının görüşleri doğrultusunda rehberler geliştirilmeli ve tüm geç etki kliniklerinde kullanılması teşvik edilmelidir. İzlemlerde kanıta dayalı rehberlerin kullanılması sağlık profesyonellerinin karar vermelerinde tutarlılığ sağlayarak bakımın kalitesini arttıracaktır. İzlemler için önerileri (değerlendirme, risklerin belirlenmesi, tarama testleri, izlem sıklığ $\mathrm{vb}$.) kanıtlarla geliştirmek sağ kalanların bakımına rehber olacak yeni yaklaşımların geliştirilmesini ve uluslararası iş birliklerinin kurulmasını sağlayacaktır.

Ülkemizde TPOG Derneği tarafından geç etkilerin izlemine ilişsin Uzun Dönem İzlem Rehberi (UDİR) geliştirilmiştir. Rehber tanı sürecinden itibaren geç etkilere ilişkin önleyici girişimlerle sağ kalan çocukları uzun dönemde izlemeyi hedeflemektedir. Rehberde sağ kalanlar için yer verilmiş olan "Hasta Tedavi Özet Formu" ile çocuk ve ailenin geç etkiler konusunda farkındalıklarının arttırılması ve takibin kolaylaştırılması hedeflenmektedir (27).

\section{Uzun dönem izlem modelleri}

Çocukluk çağı kanser tedavisi sonrası uzun dönem etkiler nedeniyle sağ kalanlar için uzun süreli izlemlerin planlanması giderek önem kazanmıştır (28). Avrupa ülkelerinde 110 merkezin dahil edildiği bir çalışmada merkezlerin \%66'sında çocuk yaş grubu için uzun süreli izlem kliniği, \%38'inde ise yetişkinler için uzun süreli izlem kliniği bulunduğu bildirilmiştir (29). Çocuk ve yetişkin izlem kliniklerinin genellikle çocuk hastanesinde bulunduğu ve izlem programlarının çocuk onkoloji uzmanı tarafindan (\%64) yürütüldüğü belirtilmiştir. Bununla birlikte uzman hemşire tarafindan yürütülen ve diğer uzmanların yer aldığı programlar da bulunmaktadır (29). Uzun süreli izlem să̆ kalanların iyi oluşlarının arttırılmasını amaçlamakta ve izlemlerde geç etkilerin tanılanması ve tedavisi, psikososyal destek-danışmanlık, sosyo-ekonomik kaynaklara yönlendirme, eğitim-mesleki ihtiyaçları destekleme, yetişkin izleme geçişi koordine etme ve sağlığın geliştirilmesine yönelik holistik bakım uygulamalarına yer verilmektedir (28,30-32). 
Derleme

Sağ kalanların izleminin sürdürülmesinde her biri farklı avantaj ve dezavantajlara sahip çeşitli modeller bulunmaktadır (Şekil 2). Sağ kalanların çocukluk, adölesan ve yetişkin dönemde izlemlerini sağlamak için mümkün olan en iyi modelin ne olduğu konusunda kesin bir görüş birliğine varılamamıştır. Çünkü sağ kalanların geçmiş tedavilerin de etkisiyle farklı gelişimsel süreçlerde sağlık bakım gereksinimleri değişmektedir ve birçok farklı yaklaşımı gerektirmektedir (33). Sağ kalan çocuk ve adölesanların izleminde kullanılan izlem modelleri Tablo 2'de verilmiştir.

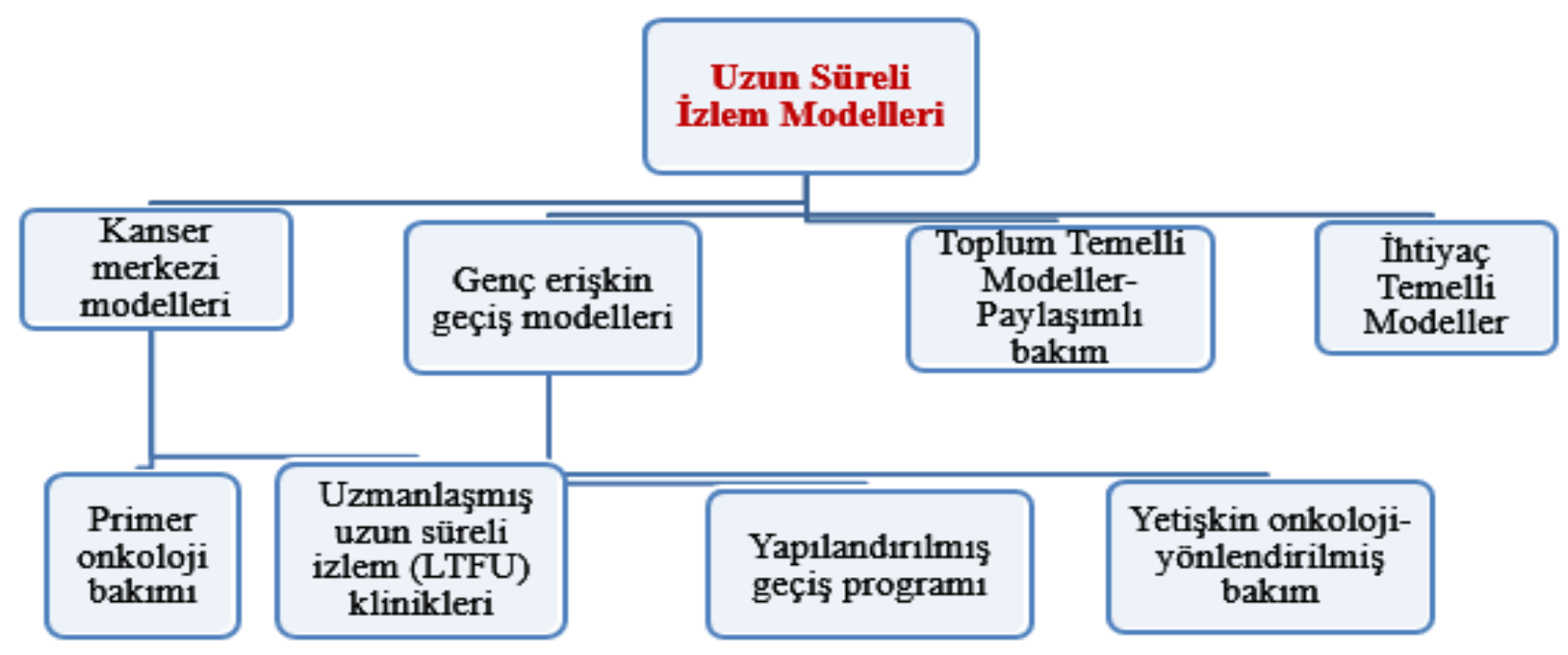

Şekil 2. Çocukluk Çă̆ı Kanserlerinden Sağ Kalanlar için Uzun Dönem İzlem Modelleri $(30,31,33)$ 


\section{Model
Kanser merkezi modelleri}

Primer onkoloji bakımı $(31,34)$

\section{Ozellikleri ve Ekip Úyeleri}

\section{Pediatrik onkoloji polikliniği}

Çocukların tedavinin tamamlanmasının ardından tedavilerinin sürdürüldüğü polikliniklerde izlemleri devam etmektedir.

Ekip; primer onkoloji uzmanı hekim

\section{Uzmanlaşmış uzun süreli Sağkalım bakımına odaklı uzun süreli izlem polikliniği}

izlem klinikleri $(31,34)$
Tedavinin tamamlanmasından 2 y1l sonra uzun sürel izlem polikliniklerine geçişleri sağlanmaktadır.

Ekip; pediatrik onkoloji hekimi, pediatrik onkolojide deneyimli/uzman hemşire, diğer uzmanlar (çocuğun gereksinmine göre endokrin uzmanı, kardiyoloji uzmanı, psikiyatrist vb.)

\section{Güçlï yönleri}

Hastalar tedavi eden hekimle güven ilişkisi geliştirmiş olduğundan bu çoğu zaman hastalar için en rahat modeldir.

Geç etkiler konusunda uzman ekip tarafindan bakım verilmekte ve sağlığın geliştirilmesi uygulamalarına odaklanılmaktadır. Sağ kalanların izlemi risk sınıflaması yapılarak hekim ve/veya hemşire tarafindan yapılmakta ve geç etkilerin riski veya varlığına göre diğer uzmanlarda izleme dahil olmaktadır.

Sağlık profesyonellerine araştırma ve eğitim başvurularını kısıtlayabilir.

\section{Zayıf yönleri} firsatlar kaçırılabilir. hissetmeyebilir. karşılayamayabilir.
İzlemlerde hastalık ve relaps üzerine odaklanılabileceği için geç etkilerin tespiti ve sağlığın geliştirilmesi ile ilgili

Sağ kalanlar yetişkin döneme
geldiklerinde pediatri kliniğinde rahat

Pediatri ekibi yetişkin dönemde sağ kalan bireyin gereksinimlerini

Să̆ kalanların aile hekimliklerine firsatları sunmaktadır.

\section{\begin{tabular}{l}
$\begin{array}{l}\text { Genç erişkin geçiş } \\
\text { modelleri }\end{array}$ \\
\hline
\end{tabular}}

Yapılandırılmış programları $(31,33)$

geçis

iş Yetiş dönemde pediatri ekibi ve yetişkin ekibinin ortaklığında yürütülmektedir.

Ekip; yetişkin onkoloji hekimi, hemşire ve/veya aile hekimliği uzmanları, diğer uzmanlar (gereksinime göre endokrin uzmanı, kardiyoloji uzmanı, psikiyatrist vb.)
Çocukluk çağı kanserlerinden sağ kalan bireylerin yetişkin

Korunaklı bir pediatrik ortamdan yetişkin ortamına geçişin sağlanması özellikle geç adölesan dönemde sağ kalanların daha bağımsız hissetmelerini ve kendi sağlıklarını sürdürme konusunda rol almalarını sağlamaktadır.

Uzun süreli bakımın sürdürülmesinde işbirlikçi ve multidisipliner yaklaşımı teşvik eder. Sağ kalanlar için yetişkin izleme geçişi kolaylaştırır ve uzun süreli izleme devamı teşvik etmektedir.

Genç erişkin săg kalanlarla araştırmaların yapılması için firsatlar sunmaktadır.

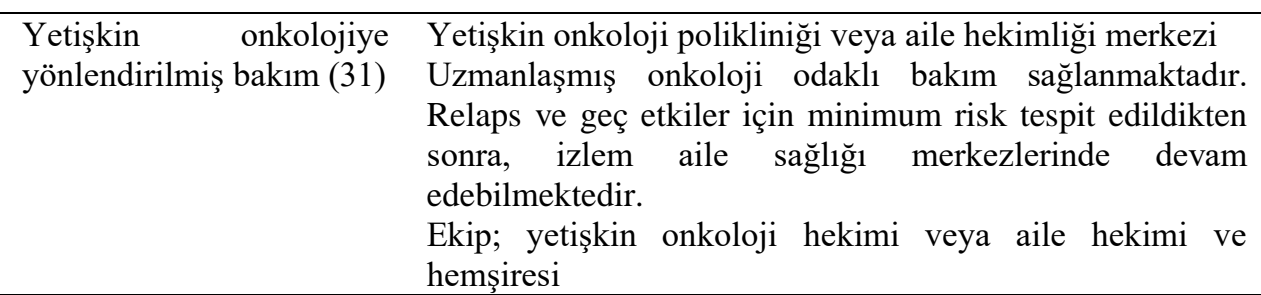

Yetişkin dönemde de onkoloji alanında uzman bakımın sunulmasını sağlar. Özellikle küçük, yerel bölgeler için uygun olabilir.
Tüm sağ kalanlar için (coğrafi ve kültürel özellikler dikkate alındığında) her zaman uygun olmayabilir.

Hastalık ve relaps odaklı bir bakım

olacă̆ için sağlığın geliştirilmesi gözden kaçabilir.

Araştırmaların yürütülmesi zor olabilir. 


\section{Toplum temelli modeller}

Toplum temelli bakım/ Pediatrik ve yetişkin birinci basamak hekimliği merkezleri Paylaşımlı bakım modeli Düşük risk grubunda olanlar ve izlemleri bitenler bu ekibe $(30,31)$

yönlendirilmektedir. Ekip bireyin risk faktörleri, beklenen geç etkiler ve tarama testleriyle ilgili pediatrik onkolojide uzman ekip tarafindan bilgilendirilir ve aile hekiminin de değerlendirme bulgularını uzun dönem izlem kliniği ile paylaşması beklenir.

Ekip; pediatri hekimi, aile hekimi ve uzman hemșire

Sag kalanların yaşadığı bölgeye yakın olması ve maliyeti en düşük ve uygulanabilir model olduğu düşünülmektedir.

Sağ kalanların birinci basamak sağlık

Çeşitli kronik durumlar (geç etkiler) için gerekli tarama testlerinin aile hekimliğ tarafindan yapılamaması kısitlılıkları

hizmetlerini kullanmalarını teșvik eder.

Aile hekimi tarafından yapılan izlem özellikle yetişkin dönemde sağ kalanlar için iyi bir alternatif olarak görülmektedir. (31) veya aile hekimliği merkezleri

Sağlık kaynaklarının daha eşit dağılımını sağlamaktadır (en fazla ihtiyacı olan sağ kalanlar

Sağ kalanların daha önce aldıkları tedavinin yoğunluğuna daha yoğun izleme alınır). göre izlemin türü ve sıklığının belirlendiği modeldir.

İlem türü; 1 . basamakta sadece cerrahi tedavi yapılmıs ya da düşük riskli kemoterapi almış bireyler yılda bir ya da iki kez telefon ya da e-mail ile; 2 . basamakta kemoterapi veya kemoterapiyle birlikte kraniyal RT almıs bireyler yılda bir ya da iki kez primer onkoloji uzmanı ve hemşiresi tarafından; 3. basamakta ise RT ve multimodal tedaviler almıs (4. Evre) bireyler y1llık olarak gec etki kliniklerinde izlemlerinin yapılması önerilmektedir.

Ekip; pediatrik onkoloji hekimi, hemşire, aile hekimi

Düşük riskli grup birinci basamakta takip edileceğinden să̆ kalanların gec etkiler yönünden daha az bakım alma riski olabilir. 
Derleme

\section{Türkiye'de să̆ kalan çocuk ve adölesanların izlemi}

Ülkemizde bazı merkezlerde geç etki kliniği bulunmakla birlikte birçok merkezde sağ kalan çocuk ve adölesanların izlemi aktif tedavi gören grubun da takip edildiği hematoloji/onkoloji polikliniklerinde yürütülmektedir (35). İzlemler primer pediatrik hematoloji/onkoloji uzmanı tarafından sağlanmakta ve izlemlerde pediatrik onkoloji alanında deneyimli hemşireler yer almamaktadır (36). İzlemlerde sağ kalanlar relaps riski, ikincil maliniteler ve geç etkilerin varlı̆̆ yönünden takip edilmektedir. Bunun yanında psikososyal sorunların varlığı durumunda ilgili birimlere yönlendirilmektedir (35,36). Sağ kalanların izlemi genç erişkin dönemine kadar sürdürülebilmekte daha sonra yetişkin kliniklerine devredilmektedir. Uygulamada gözlenen en önemli sorunlardan biri să̆ kalanların yetişkin kliniklerine devrinin etkin bir şekilde yapılamamasıdır (35). Ülkemizde tedavi sonrası izlemin etkinliğinin arttırılması için ulusal uzun süreli izlem rehberlerinin geliştirilmesi gerektiği vurgulanmaktadır (36). Bu amaçla TPOG Derneği tarafından uzun dönem izlem rehberi geliştirilmiştir ve izlem kliniklerinde kullanımının yaygınlaştırılması planlanmaktadır (27).

Sağ kalanların izlemi yaşam boyu çocukluktan ergenliğe ve daha sonra yetişkinliğe geçerken değişen ihtiyaçları karşılamak için farklı yaklaşımları barındırmalıdır. Hangi izlem modeli kullanılırsa kullanılsın en önemli noktalardan biri sağ kalan çocuk ve adölesanların kendi izlem ve bakımına aktif katılımının desteklenmesidir. Sağ kalanların izleminde uygun modelin belirlenmesinde mevcut kaynaklar ve bu kaynakların kullanımı için belirli prosedürler gözden geçirilerek ekip iş birliği ile karar verilmesi uygun olacaktır.

\section{Çocukluk Çăğ Kanserlerinden Să̆ Kalanların İzleminde Pediatri Hemşiresinin Rolü}

Çocukluk çağı kanserlerindeki bu gelişmeler ışığında hemşirelik bakımının kapsamı genişlemiş ve yeni bir boyut kazanmıştır. Pediatri hemşiresi sağ kalan çocukların tedavi sonrası süreçte, geç etkilerinin erken saptanması, sosyal yaşama uyumlarının kolaylaştırılması, sağlığı geliştirici davranış kazandırılması ve bu doğrultuda yaşam kalitelerinin iyileştirilmesi amacıyla holistik bakımın sunulmasından sorumludur. Güncel rehberlerde izlemlerin hemşirenin yer aldığ multidisipliner ekip tarafından yürütülmesi önerilmektedir (2,29). Gelişmiş ülkelerde hemşireler izlemlere 30 yılı aşkın süredir dahil olmuştur (37) ve bazı merkezlerde risk grubuna göre sağ kalanların izlemi hemşire tarafından yürütülmektedir (31). Birçok izlem kliniğginde multidisipliner ekibin üyesi olan hemşire sağ kalanların izlemlere katılımını teşvik etmekte ve hasta ile ekip üyeleri arasında iletişimi koordine etmektedir (31). İzlemi yürüten pediatri hemşiresinin sağ kalan çocuk ve adölesanda potansiyel geç etkiler ve izlem konusunda yeterli bilgi, klinik deneyim ve yetkinliğe sahip olması beklenmektedir. Pediatri hemşiresinin profesyonel rolleri doğrultusunda izlemlerdeki rol ve sorumlulukları aşağıda verilmiştir (Şekil 3).

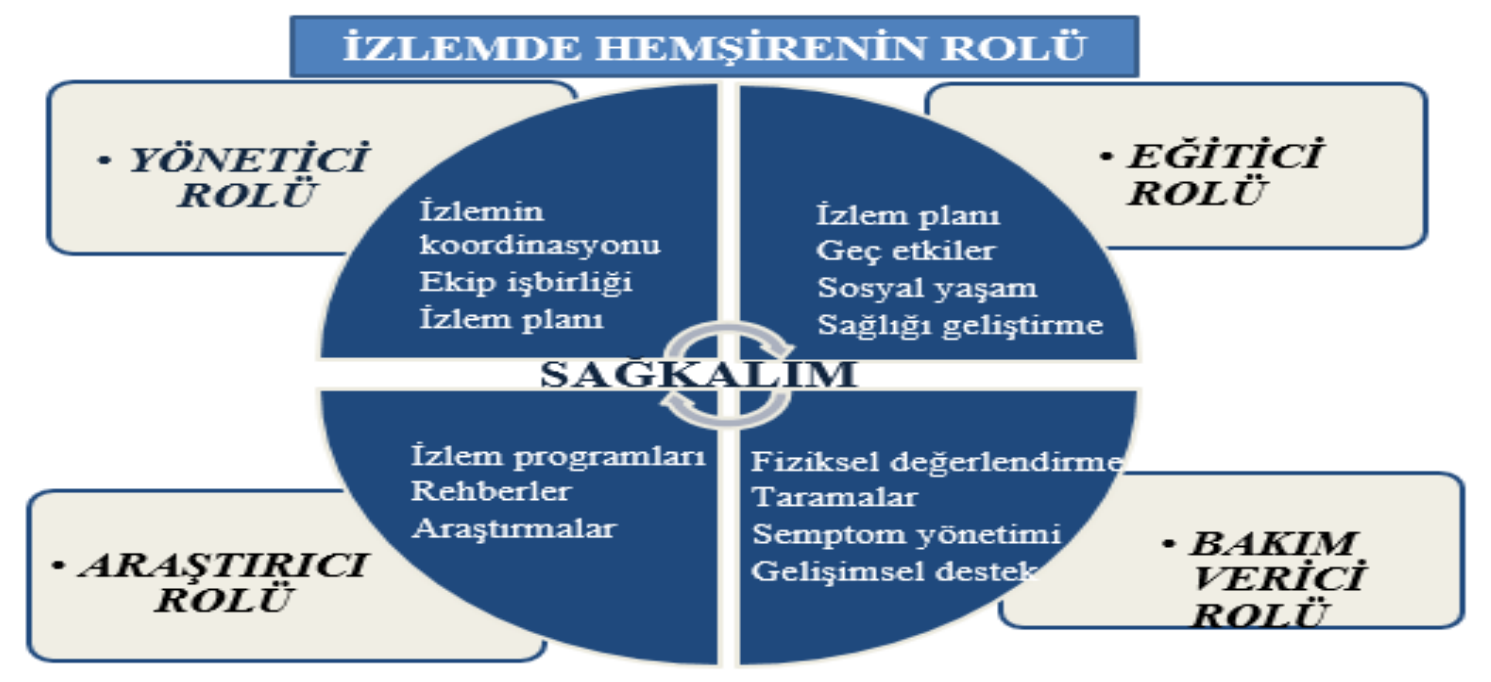

Şekil 3. İzlemlerde Pediatri Hemşiresinin Profesyonel Rollerinin Kapsamı (31,32,47,50) 
Derleme

Koordinatör rolü: İzlem sürecinde çocuk ve adölesanların hemşirelik bakımına ilişkin düzenli ve kapsamlı planlamalar yapılmalıdır. Pediatri hemşiresi koordinatör rolüyle bakımın koordinasyonunu sağlayarak izlemlerin etkili sürdürülmesini sağlamalıdır. Bireyselleştirilmiş bakım planları doğrultusunda sağ kalanların hangi ekip tarafından ve ne sıklıkla izleneceği, hangi taramaların ve değerlendirmelerin yapılması gerektiğini belirleyerek ekibi bilgilendirebilir. Bunun yanında izlem klinikleri arasında koordinasyonu sağlayarak ekip iş birliğinin sürdürülmesini kolaylaştırabilir (31).

Eğitici rolü: Hydeman ve diğerlerinin (38) sağ kalanların gereksinimlerini değerlendirdikleri çalışmada sağ kalanların sıklıkla tanı, tedavi ve gelişebilecek potansiyel geç etkiler hakkında yeterli bilgi sahibi olmadıklarını belirlemişlerdir. Başka bir çalışmada benzer şekilde sağ kalanların spesifik tedavileri, önerilen izlem planı ve önemi, geç etkiler ve spesifik riskleri ve yaşam tarzı konusunda sürekli eğitime ihtiyaç duydukları bildirilmiştir (39). Săg kalanların gereksinimlerinin tedavinin psikososyal, duygusal ve bilişsel etkileriyle ilişkili olduğu gözlenmiştir. Bununla birlikte kimlik kazanımı, ekonomik yük ve doğurganlık gibi gelişimsel kaygılarının da olduğu bildirilmiştir (38). Pediatri hemşiresi bakım hedefleri doğrultusunda eğitici rolünü üstlenerek sağ kalan çocuk ve adölesanların ve ebeveynlerin bilgi gereksinimlerini değerlendirmeli ve hazır oluşluklarına göre açık ve dürüst bir yaklaşımla bireyselleştirilmiş tekrarlı eğitimler düzenlemelidir.

Pediatri hemşiresi tüm yaş gruplarında büyüme ve gelişmeye hakim olmalı ve bu doğrultuda sağlı̆̆ın sürdürülmesi konusunda yaklaşımlar geliştirmelidir. Çocukluk çağında kanser gibi yaşamı tehdit edici hastalık tanısı almak gelişimsel süreçleri değiştirebilmektedir. Bu nedenle çocuk ve adölesanlar dönemin gelişimsel görevlerini yerine getiremeyebilir (40). Örneğin okul çağında tanı alan veya tedavisi tamamlanan çocukların sosyalleşme ve başarı gibi dönemin temel özelliklerini pekiştiren-destekleyen okul ortamından uzak kalmaları çocuklarda yetersizlik inancının gelişmesine neden olabilir. Çocukluktan yetişkinliğe geçiş dönemi olan adölesan dönemde ise ben kavramı ön plana çıkar ve aileden bağımsızlık önem kazanır. Buna karşın kanser öyküsü olanlar duygusal ve fiziksel destek ihtiyacı nedeniyle akranlarına kıyasla ebeveynlerine bağımlıdır $(38,41)$. Bu durum adölesanın normal rutinlerine dönmesi ve bağımsızlaşmasını olumsuz etkilemektedir. Adölesanlar geleceğe ilişkin belirsizlik nedeniyle kaygı yaşayabilir ve bu durum adölesanın kimlik karmaşası yaşamasına neden olabilir $(38,42)$. Sağ kalanların bakım planlamalarında gelişimsel kaygıların ele alınması büyük önem taşımaktadır. Hemşire çocukların gelişimsel dönem özellikleri ve kronik hastalığın gelişime etkisi konusunda çocuk ve ebeveynlere danışmanlık vermeli, çocukların gelişimsel ihtiyaçlarının karşılanması için ebeveynleri desteklemelidir.

Sağ kalanların uzun süreli izlemlere katılımlarının sağlanması oldukça önemlidir. Bazı çalışmalarda belirli düzeyde adölesan ve yetişkin sağ kalanların uzun dönemde izlemlere devam etmedikleri bildirilmektedir $(39,43,44)$. Tedavi sonrası ilk yıllar önemli bir kısmı izleme devam ederken (\%88) ilerleyen yıllarda izlemlere katılımın azaldığı (10 yıl ve sonrası \%48) bildirilmiştir (36). Lupatsch ve diğerleri (45) tedavisi en az 5 yıldır tamamlanan sağ kalan adölesanların \%56'sının izlemlere devam ettiğini belirlemişlerdir. İzlemlere katılımı izlemler konusunda yeterli bilgiye sahip olmama (39), izlemlere yönelik algılanan yarar (erken tanı)-engeller (izlemlerin gerekli olmadığg düşüncesi, geç etki saptanacağı korkusu) (43) ve sağlık inanç ve algılarının $(43,45)$ etkileyebileceği bildirilmektedir. Pediatri hemşiresi uzun süreli izlemin amacı, neleri kapsadığı ve süresi konusunda sağ kalanları ve ebeveynleri bilgilendirmelidir. Bunun yanında izlemlere katılım, kendi sağlığını yönetme ve bağımsız kararlar alma konusunda sağ kalanları teşvik etmelidir. Genç erişkin dönemde yetişkin kliniklerine geçişe ve izlemi bitenleri de taburculuğa hazırlamalıdır.

Bakım verici rolü: Hastalık ve tedavi süreci nedeniyle gelişen sorunlara (anükleasyon, ampütasyon, Hemopoetik Kök Hücre Transplantasyonu sonrası sorunlar gibi) bağlı olarak çocuk ve adölesanların yaşadıkları sorunlar özelleşmektedir. Hemşire să̆ kalanların farklılaşan bu özel gereksinimlerine yönelik bakım uygulamalarını planlamalı çocuk ve ailenin gerekli desteği alabilmesi için girişimlerde bulunmalıdır. Her izlemde potansiyel riskleri göz önünde bulundurarak fiziksel değerlendirme yapmalıdır. Fiziksel ve psikososyal geç etkilerin erken dönemde saptanması için hemşire bakım verici rolü ile çocuk ve adölesanların geçmiş tıbbi öyküsü ve aldığı tedavileri gözden geçirerek gerekli taramaları (Boy-kilo ölçümü, kan basıncı ölçüm, kalp sesleri, endokrin testler vb.) yapmalı, semptom yönetimi konusunda danışmanlık vermeli ve gerekli tedavileri uygulamalıdır $(31,46,47)$.

Pediatri hemşiresi sağ kalanları ve bakım verenleri psikososyal sorunlar ve bunların etkileri yönünden değerlendirmelidir. Sağ kalanların başa çıkma becerileri, aile ve akran ilişkilerini değerlendirmeli ve aile merkezli bakım esas alınarak danışmanlık vermelidir. Gerekli durumlarda profesyonel destek almalarını sağlamalıdır. Akran destek grupları oluşturup yönetimini sağlayarak sağ kalanların ve ebeveynlerin deneyimlerini paylaşabileceği, aynı zamanda çeşitli sorunlara çözüm üretebileceği firsatlar sunmalıdır.

Araştırıcı rolü: Hemşire sağ kalanların destek sistemlerine yeterli düzeyde ulaşabilmesi için diğer ekip üyeleriyle klinik değerlendirme ve bakımda kullanılacak rehberlerin hazırlanması ve yönetim planının geliştirilmesinde rol almalıdır. İzlemlerin ve bakımın etkinliği düzenli olarak yapılacak denetleme çalışmalarıyla değerlendirilmeli ve sonuçlar doğrultusunda izlemlerin standartları gözden geçirilmelidir. Sağ kalanların ve ebeveynlerin gereksinimlerinin belirlenmesi için tanımlayıcı çalışmalar planlanmalı ve bulgular doğrultusunda bakım planları ve eğitim programları güncellenmelidir.

Sağ kalanlarının iyilik halinin sürdürülmesi için izlemleri kanıt temelli uygulamalarla desteklemek öncelikli hale gelmiştir. Literatürde hemşireler tarafından izlemlerin etkinliğini arttırmak ve sağ kalanlara sağlık eğitimi (48) ve psikososyal destek sağlanmasına yönelik yeni girişimler geliştirildiği görülmektedir (49). Bakım verilen popülasyonun gereksinimleri ve mevcut kaynaklar göz önüne alınarak bakımın sunulmasında farklı yöntemler kullanılabilir. İzlemlerde teknoloji destekli uygulamalar bu yaklaşımlardan biridir. Bu sayede să̆ kalanların belirli alanlarda daha hızlı değerlendirilmesi ve bilgiye ulaşmaları kolaylaşabilir. Web-mobil destekli uygulamalar (video konferans, sosyal medya, internet, web programları) sağ kalanların genel sağlığının değerlendirilmesi amacıyla veri toplama, psiksosyal destek, eğitim ve danışmanlık alanlarında kullanılabilmektedir (50). Hemşire bu tarz uygulamaların geliştirilmesi, randomize kontrollü araştırmalarla test edilmesi ve bakıma entegre edilmesine öncülük edebilir. 
Sonuç olarak çocukluk çağı kanserlerinden sağ kalanlarda uzun dönemde morbiditenin önlenmesi ve psikososyal iyilik halinin arttırılması için hemşirelere önemli roller düşmektedir. Sağ kalan çocukların tedavi sonrası sürece hazırlanması, danışmanlık almak için desteklenmeleri ve tüm aile üyeleriyle birlikte genel iyilik hallerinin düzenli olarak değerlendirilmesi gerekmektedir. Hemşirelik bakımı çocukların ve adölesanların gelişimsel ihtiyaçlarını göz önünde bulundurarak, dürüst yaklaşım, karar verme süreçlerine katma ve sağlıklı davranış geliştirme ve sürdürme konusunda stratejiler geliştirmeyi içermelidir. Ülkemizde gelişim aşamasında olan uzun dönem izlem kliniklerinde hemşirenin yer almasını teşvik edecek stratejiler geliştirilmeli ve diğer ekip üyeleriyle iş birliği sağlanmalıdır. Pediatrik onkoloji alanında deneyimli hemşirelerin hizmet içi eğitimler ve çeşitli sertifika programlarıyla să kalanların izlemi ve hemşirenin rolleri konusunda yetkinlik kazanmaları önerilmektedir.

\section{Bilgilendirme}

Bu derlemeye yazarların katkı oranı beyanı şu şekildedir: fikir ve kavram T.A., N.A.; tasarım T.A.; denetleme N.A.; literatür tarama T.A.; literatür verilerinin analizi ve yorumlaması T.A., N.A.; makalenin yazımı T.A., N.A.; eleştirel düşünme T.A., N.A. Bu derleme, araştırma ve bilimsel yayın etiğine uyularak yazılmıştır. Araştırmacılar arasında herhangi bir çıkar çatışması bulunmamaktadır. Derleme yazımı ile ilgili herhangi bir kurum ya da kuruluştan destek alınmamıştır.

\section{Kaynaklar}

1. Lown E, Phillips F, Schwartz LA, Rosenberg AR, Jones B. Psychosocial follow-up in survivorship as a standard of care in pediatric oncology. Pediatr Blood Cancer 2015; 62(S5): S514-S584.

2. Children's Oncology Group. Long-term follow-up guidelines for survivors of childhood, adolescent and young adult cancers, version 5.0. Monrovia, CA: Children's Oncology Group; 2018. Available from: http://www.survivorshipguidelines.org/pdf/2018/COG_LTFU_Guidelines_v5.pdf

3. American Cancer Society (2020). Cancer facts \& figures. Available from: https://www.cancer.org/research/cancer-factsstatistics/all-cancer-facts-figures/cancer-facts-figures-2020.html

4. Kutluk MT, Yesilipek A. Turkish National Pediatric Cancer Registry 2002-2008 (Turkish Pediatric Oncology Group and Turkish Pediatric Hematology Society). J Clin Oncoly 2013; 31(15_suppl): 10067 (abstr).

5. Armstrong GT, Chen Y, Yasui Y, Leisenring W, Gibson TM, Mertens AC, et al. (2016). Reduction in late mortality among 5-year survivors of childhood cancer. New England Journal of Medicine, 374(9), 833-842.

6. Langer T, Grabow D, Steinmann D, Wörmann B, Calaminus G. Late effects and long-term follow-up after cancer in childhood. Oncol Res Treat 2017; 40(12): 746-750.

7. Gibson TM, Li C, Armstrong GT, Srivastava DK, Leisenring WM, Mertens A, et al. Perceptions of future health and cancer risk in adult survivors of childhood cancer: A report from the Childhood Cancer Survivor Study. Cancer, 2018; 124(16): 3436-3444.

8. Essig S, Li Q, Chen Y, Hitzler J, Leisenring W, Greenberg M, et al. Estimating the risk for late effects of therapy in children newly diagnosed with standard risk acute lymphoblastic leukemia using an historical cohort: A report from the Childhood Cancer Survivor Study. Lancet Oncol 2014; 15(8): 841-51.

9. Bhakta N, Liu Q, Ness KK, Baassiri M, Eissa H, Yeo F, et al. The cumulative burden of surviving childhood cancer: an initial report from the St Jude Lifetime Cohort Study (SJLIFE). Lancet, 2017; 390(10112): 2569-2582.

10. Arpaci T, Toruner, EK. Assessment of problems and symptoms in survivors of childhood acute lymphoblastic leukaemia. Eur J Cancer Care 2016; 25(6): 1034-1043.

11. Bitsko MJ, Cohen D, Dillon R, Harvey J, Krull K, Klosky JL. Psychosocial late effects in pediatric cancer survivors: A report from the Children's Oncology Group. Pediatr Blood Cancer, 2016; 63(2): 337-343.

12. Arpaci T, Toruner EK. Quality of life in survivors of childhood cancer: Literature review/Kanserden sag kalan cocuklarda yasam kalitesi: Literatur taramasi. Journal of Education and Research in Nursing, 2017; 14(1): 86-93.

13. Kızmazoğlu D, Sarı S, Evim SM, Kantarcıŏlu A, Tüfekçi Ö, Demir YF, et al. Assessment of health-related quality of life in pediatric acute lymphoblastic leukemia survivors: Perceptions of Children, Siblings, and Parents. Turk J Haematol 2019; 36(2): 112-116.

14. Brinkman TM, Recklitis CJ, Michel G, Grootenhuis MA, Klosky JL. Psychological symptoms, social outcomes, socioeconomic attainment, and health behaviors among survivors of childhood cancer: current state of the literature. J Clin Oncol 2018; 36(21): 2190.

15. Kosir U, Wiedemann M, Wild J, Bowes L. Psychiatric disorders in adolescent cancer survivors: A systematic review of prevalence and predictors. Cancer Rep 2019; 2(3): e1168.

16. Yi J, Kim MA, Hong JS, Akter J. Childhood cancer survivors' experiences in school re-entry in South Korea: Focusing on academic problems and peer victimization. Child Youth Serv Rev, 2016; 67: 263-269.

17. An H, Lee S. Difficulty in returning to school among adolescent leukemia survivors: A qualitative descriptive study. Eur J Oncol Nurs 2019; 38: 70-75.

18. Kim Y, Lee KS, Koh KN. Difficulties faced by long-term childhood cancer survivors: A qualitative study. Eur J Oncol Nurs 2018; 36: 129-134.

19. Smith WA, Li C, Nottage KA, Mulrooney DA, Armstrong GT, Lanctot JQ, et al. Lifestyle and metabolic syndrome in adult survivors of childhood cancer: a report from the St. Jude Lifetime Cohort Study. Cancer 2014; 120(17): $2742-2750$.

20. Paxton RJ, Jones LW, Rosoff PM, Bonner M, Ater JL, Demark-Wahnefried W. Associations between leisure-time physical activity and health-related quality of life among adolescent and adult survivors of childhood cancers. Psychooncology, 2010; 19(9): 997-1003. 
Derleme

21. Tonorezos ES, Robien K, Eshelman-Kent D, Moskowitz CS, Church TS, Ross R, et al. Contribution of diet and physical activity to metabolic parameters among survivors of childhood leukemia. Cancer Causes Control 2013; 24(2): $313-321$.

22. Tylavsky FA, Smith K, Surprise H, Garland S, Yan X, McCammon E, et al. Nutritional intake of long-term survivors of childhood acute lymphoblastic leukemia: evidence for bone health interventional opportunities. Pediatr Blood Cancer 2010; 55(7), 1362-1369.

23. Rebholz CE, Kuehni CE, Strippoli MPF, Rueegg CS, Michel G, Hengartner H, et al. Alcohol consumption and binge drinking in young adult childhood cancer survivors. Pediatr Blood Cancer, 2012; 58(2): 256-264.

24. Klosky JL, Howell CR, Li Z, Foster RH, Mertens AC, Robison LL, et al. Risky health behavior among adolescents in the childhood cancer survivor study cohort. J Pediatr Psychol 2012; 37(6): 634-646.

25. Kopp LM, Gastelum Z, Guerrero CH, Howe CL, Hingorani P, Hingle M. Lifestyle behavior interventions delivered using technology in childhood, adolescent, and young adult cancer survivors: a systematic review. Pediatr Blood Cancer 2017; 64(1): 13-17.

26. Landier W, Skinner R, Wallace WH, Hjorth L, Mulder RL, Wong FL, et al. Surveillance for late effects in childhood cancer survivors. J Clin Oncoly 2018; 36(21): 2216.

27. Uzun Dönem İzlem Rehberi, UDİR, 2020. Türk Pediatrik Onkoloji Grubu Derneği. Son erişim tarihi: 20.08.2020 http://www.tpog.org.tr/uploads/Link_1_Onsoz_UDiR_Yan_Etki_Izlemi2.pdf

28. Signorelli C, Wakefield CE, Fardell JE, Wallace WHB, Robertson EG, McLoone JK, et al. The impact of long-term follow-up care for childhood cancer survivors: A systematic review. Crit Rev Oncol Hematol 2017; 114: $131-138$.

29. Essig S, Skinner R, von der Weid NX, Kuehni CE, Michel G. follow-up programs for childhood cancer survivors in Europe: A Questionnaire Survey. PLoS ONE, 2012; 7(12): e53201.

30. Singer S, Gianinazzi ME, Hohn A, Kuehni CE, Michel G. General practitioner involvement in follow-up of childhood cancer survivors: a systematic review. Pediatr Blood Cancer, 2013; 60: 1565-1573.

31. Landier W. Establishing and enhancing services for childhood cancer survivors: long-term follow-up program resource guide. Children's Oncology Group; Arcadia, CA; $2007 . \quad$ Available from: http://www.survivorshipguidelines.org/pdf/ltfuresourceguide.pdf

32. American Academy of Pediatrics Section on Hematology/Oncology Children's Oncology Group. Long-term follow-up care for pediatric cancer survivors. Pediatrics 2009; 123(3): 906-915.

33. Frey E, van der Pal H. Transitional care of a childhood cancer survivor to adult services: facilitating the process of individual access to different models. Curr Opin Support Palliat Care 2013; 7(3): 309-313.

34. Heirs M, Suekarran S, Slack R, Light K, Gibson F, Glaser, et al. A systematic review of models of care for the follow-up of childhood cancer survivors. Pediatr Blood Cancer 2013; 60(3): 351-356.

35. Özdemir Sİ, Taçyildiz N, Varan A, Kebudi R, Zülfikar OB, Celkan T, et al. Cross-sectional study: long term follow-up care for pediatric cancer survivors in a developing country; Turkey: current status, challenges and future perspectives. Turk J Med Sci 2020 Jul 6. doi: 10.3906/sag-1911-193. Epub ahead of print. PMID: 32628434.

36. Tacyildiz N, Ozdemir SI, Unal EC, Dincaslan H, Yavuz G. Barriers and solutions of long-term follow up of childhood cancer survivors in Turkey: A questionaire survey. J Clin Oncol 2017; 35(15_suppl): e22020.

37. Hobbie WL. The role of Pediatric Oncology Nurse Specialist in a Follow-up Clinic for Long-term Survivors of Childhood Cancer. J Assoc Pediatr Oncol Nurses 1986; 3(4): 9-12.

38. Hydeman JA, Uwazurike OC, Adeyemi EI, Beaupin LK. Survivorship needs of adolescent and young adult cancer survivors: a concept mapping analysis. J Cancer Surviv 2019; 13(1): 34-42.

39. Ford JS, Chou JF, Sklar CA. Attendance at a survivorship clinic: impact on knowledge and psychosocial adjustment. J Cancer Surviv 2013; 7(4): 535-43.

40. Kim DH, Yoo IY. Factors associated with resilience of school age children with cancer. J Paediatr Child Health 2010; 46(7-8): 431-436.

41. Keene N, Hobbi, W, Ruccione K. Survivorship. Childhood cancer survivors: A practical guide to your future (3rd ed.). Bellingham, WA: Childhood Cancer Guides; 2012. p. 1-27.

42. Mertens AC, Brand S, Ness KK, Li Z, Mitby PA, Riley A, et al. Health and well-being in adolescent survivors of early childhood cancer: a report from the Childhood Cancer Survivor Study. Psychooncology, 2014; 23(3): 266-275.

43. Michel G, Kuehni CE, Rebholz CE, Zimmermann K, Eiser C, Rueegg CS, et al. Can health beliefs help in explaining attendance to follow-up care? The Swiss childhood cancer survivor study. Psychooncology 2011; 20(10): 1034-43.

44. Vetsch J, Rueegg CS, Mader L, Bergstraesser E, Rischewski J, Kuehni CE, et al. Follow-up care of young childhood cancer survivors: attendance and parental involvement. Support Care Cancer, 2016; 24(7): 3127-38.

45. Lupatsch JE, Wengenroth L, Rueegg CS, Teuffel O, Gumy-Pause F, Kuehni CE, et al. Follow-up care of adolescent survivors of childhood cancer: The role of health beliefs. Pediatr Blood Cancer, 2016; 63(2): 318-325.

46. Shepherd EJ, Woodgate RL. Cancer survivorship in children and young adults: a concept analysis. J Pediatr Oncol Nurs 2010; 27(2): 109-118.

47. Haupt R, Essiaf S, Dellacasa C, Ronckers CM, Caruso S, Sugden E, et al. The 'Survivorship Passport' for childhood cancer survivors. Eur J Cancer 2018; 102: 69-81.

48. Signorelli C, Wakefield CE, Johnston KA, Fardell JE, Brierley MEE, Thornton-Benko, et al. 'Re-engage'pilot study protocol: a nurse-led eHealth intervention to re-engage, educate and empower childhood cancer survivors. BMJ open, 2018; 8(4): e022269. 
Derleme

49. Bouwman E, Hermens RP, Blijlevens NM, Prins JB, Loonen JJ. Nurse-led video-coaching interventions in childhood, adolescent and young adult cancer survivors (REVIVER): a protocol for mixed methods feasibility research. Pilot Feasibility Stud 2019; 5(1): 150.

50. Toruner EK, Altay N. New trends and recent care approaches in pediatric oncology nursing. Asia Pac J Oncol Nurs 2018; 5(2): 156. 